\title{
Men and Women Pursue Nonlinear Career Paths, but Impacts Differ: a Cross-Sectional Study of Academic Hospitalists
}

\author{
Maya V. Defoe, $M D^{7}$ (D), Kenzie A. Cameron, $P h D, M P H^{2}$, Marisha Burden, $M D^{3}$, \\ Sophia R. Mazurek, BS', John A. Updike, MD, MPH', Angela Keniston, $\mathrm{MSPH}^{3}$, \\ Kevin J. O'Leary, $M D, M S^{7}$, and Jennifer A. Best, $M D^{4}$
}

\begin{abstract}
'Division of Hospital Medicine, Northwestern University Feinberg School of Medicine, Chicago, IL, USA; ${ }^{2}$ Division of General Internal Medicine and Geriatrics, Northwestern University Feinberg School of Medicine, Chicago, IL, USA; ${ }^{3}$ Division of Hospital Medicine, University of Colorado School of Medicine, Aurora, IL, USA; ${ }^{4}$ Department of Medicine, University of Washington School of Medicine, Seattle, WA, USA.
\end{abstract}

\begin{abstract}
BACKGROUND: Nonlinear career paths are increasingly common. Women in academia pursuing nonlinear career paths experience negative impacts on career trajectory. No published studies have examined how pursuit of nonlinear career paths might perpetuate gender inequities within academic hospital medicine.

OBJECTIVE: (1) Compare the frequency of nonlinear career paths by gender among academic hospitalists; (2) assess the perceived impact of two types of nonlinear career paths-extended leave (EL) and non-traditional work arrangements (NTWA) on hospitalists' personal lives and careers.
\end{abstract}

DESIGN, SETTING, AND PARTICIPANTS: Cross-sectional descriptive survey study of adult hospitalist physicians in three academic centers within the USA.

INTERVENTION: Electronic survey including closed- and open-ended items assessing respondent utilization of and experiences with nonlinear career paths.

MAIN OUTCOMES AND MEASURES: (1) Associations between EL and demographic variables as well as gender differences in leave length and NTWA strategies using Fisher's exact test; 2) grounded theory qualitative analysis of open-text responses.

KEY RESULTS: Compared with men, women reported taking EL more often ( $p=0.035)$ and for longer periods $(p=0.002)$. Men and women reported taking NTWA at similar rates. Women reported negative impacts of EL within domains of personal life, career, well-being, and work-life integration whereas men only reported negative impacts to career. Men and women described positive impacts of NTWA across all domains.

CONCLUSIONS: Women academic hospitalists reported taking EL more often than men and experienced disproportionately more adverse impacts to personal lives and careers. Surprisingly, men reported taking NTWA to address burnout and childbirth at similar rates to women. Our findings lay the groundwork for additional exploration of cultural and policy interventions, particularly improved paid leave policies.

KEY WORDS: Gender disparities; Hospital medicine; Nonlinear career.

Received June 15, 2021

Accepted January 5, 2022

Published online January 28, 2022
$\mathrm{J}$ Gen Intern Med 37(12):3097-104 DOI: $10.1007 / \mathrm{s} 11606-022-07402-\mathrm{x}$

(C) The Author(s) under exclusive licence to Society of General Internal Medicine 2022

\section{INTRODUCTION}

An early description of the hospital medicine career predicted potential for enhanced satisfaction, focused clinical competence, and a better-defined schedule than "traditional GIM practice."1 Yet even early on, concerns existed regarding hospitalist susceptibility to burnout, which have since been demonstrated. In 2011, nearly a quarter of surveyed academic hospitalists reported burnout symptoms. ${ }^{2}$ Lack of personal and family time related to weekend and evening clinical responsibilities and lack of control over work schedule predicted burnout and low job satisfaction. ${ }^{2}$ More recent surveys demonstrate that burnout disproportionately impacts women physicians. ${ }^{3}$ Women physician-scientists assume more parenting and household responsibilities, ${ }^{4}$ struggling most with worklife integration. ${ }^{5}$

These challenges, compounding implicit and explicit biases and a lack of transparent equitable processes that mitigate bias, may contribute to medicine's observed gender disparities. ${ }^{6,7} \mathrm{~A}$ small body of research has explored gender inequities among academic hospitalists within leadership, scholarly productivity, ${ }^{8}$ and income. ${ }^{9}$ Women may consider career redefinition an alternative to attrition, ${ }^{10}$ via nonlinear career paths.

Nonlinear career paths, defined as extended leave (EL) and flexible work arrangements, ${ }^{11}$ are increasingly common. ${ }^{12}$ Women physicians are more likely than men to reduce work hours to part time. ${ }^{10}$ Economist Sylvia Ann Hewlett wrote that more than $60 \%$ of highly qualified women have nonlinear careers, ${ }^{13}$ a finding that is consistent regardless of family status. ${ }^{14}$ Yet, Hewlett also theorized that nonlinear career paths could lead to decreased retention of women in the workforce and fewer women within leadership. ${ }^{11,15}$ No prior studies have evaluated nonlinear career paths in academic hospital medicine - a field characterized by a predominantly shift-based schedule. While there is evidence that women in 
academia pursuing nonlinear career paths experience negative impacts on career trajectory, ${ }^{14,16}$ no published studies have examined nonlinear career path utilization by gender and whether these may contribute to gender inequities within academic hospital medicine.

The primary goal of this pilot study was to compare the frequency with which academic hospitalist physicians pursue nonlinear career paths by gender and to identify gender differences in key determinants of these decisions. The secondary goal was to assess the perceived impact of two types of nonlinear career paths-ELand/ornon-traditional work arrangements (NTWA) - on hospitalists' personal lives and careers, and whether these differ by gender.

\section{METHODS}

\section{Study Design and Sites}

This is a cross-sectional descriptive study of hospitalist physicians in three academic centers across the USA. Each site employs hospitalists with varying career concentrations including clinically focused faculty, clinician-educators, and physician-scientists. Each hospitalist group delivers care on teaching and non-teaching general medicine services, perioperative co-management, and specialty-based hospital medicine services. The sites were similar in size with 94 hospitalists employed at site 1, 103 at site 2, and 78 at site 3. Full-time pediatric hospitalists, full-time palliative care physicians, and advanced practice providers within hospitalist divisions were excluded.

\section{Survey Development}

The authors developed a survey based on data from Hewlett et al.'s research report "The Hidden Brain Drain." 11 A multidisciplinary team with experience in gender equity research (MB; JAB), academic hospital medicine (MVD; JAB; MB; $\mathrm{KJO}$ ), qualitative methods (JAB; KAC), and survey design (KAC; KJO; AK) developed the survey within REDCap, which included closed- and open-ended items to assess utilization of and experiences with nonlinear career paths within academic hospital medicine. Survey items were categorized within four sections: (1) EL; (2) NTWA; (3) institutional culture ${ }^{17}$ and (4) demographics. To mitigate stereotype threat in responses,${ }^{18}$ participants provided demographics at the end of the survey. ${ }^{19}$ See Appendix A for the complete survey.

EL was defined as an absence from the respondent's current employment for at least 30 days - a minimum duration inclusive of most maternity leaves. ${ }^{20}$ NTWA was defined as any choice a respondent may take that diverged from "traditional" schedules and/or responsibilities of the current hospitalist position, as institutionally stipulated. A "traditional" hospitalist schedule consists of alternating weeklong clinical and nonclinical blocks, though organizational schedules vary. Though Hewlett referenced "flexible work arrangements," survey substituted "non-traditional work arrangements" as a more inclusive characterization encompassing the many strategies hospitalists use to modify schedules and careers based on personal and professional priorities.

\section{Survey Administration}

A site champion emailed a survey link to eligible participants at each institution with language explaining the study's purpose. The email explained that by continuing with the voluntary survey, participants inherently provided consent to study participation. The link launched on July 13, 2020, for 21 days. Participants received email reminders at 7 and 14 days. All sites' institutional review boards (IRB) deemed this study exempt. Responses were anonymous and stored online via REDCap. Datasets are available from the corresponding author on reasonable request.

Site champions contacted program administrators of their respective hospitalist groups to obtain leave policies, gender distributions of eligible respondents, and de-identified grouplevel data regarding maternity/paternity, family, and personal leave lengths 3 years prior to survey administration (January 1, 2017 , to July 1,2020 ).

\section{Analysis}

Descriptive statistics were calculated for all variables of interest using Fisher's exact test. Categorical variables were summarized with counts and percentages. We examine associations between EL and demographic variables and assess for differences in EL utilization by gender. We excluded respondents choosing "prefer not to answer" to describe gender. We examined the association between gender and experience with NTWA. Additionally, we categorized NTWA strategies into three groups based on the presumed likelihood of positive, negative, or neutral career impacts, examining the positive and negative groups' association with gender also using Fisher's exact test.

Our team employed grounded theory qualitative analysis ${ }^{21}$ to categorize and interpret responses to open-text questions. We derived codes inductively from respondent survey comments, avoiding a priori hypotheses, preconceived categories, or theoretical perspectives.

Three researchers, MVD (hospitalist, assistant professor-identifying as a woman; one EL for childbearing), JAU (hospitalist, instructor - identifying as a man; with one EL for childrearing), and JAB (hospitalist, associate professor-identifying as a woman, with one EL for childbearing) independently read all comments to contextualize the body of data. All initial coding was blinded to respondent gender. Each researcher open coded an overlapping subset of responses and subsequently discussed impressions with the coding group to triangulate preliminary initial descriptive codes. All comments were then coded independently by each member of the group, who refined the coding framework in an iterative fashion, using the constant comparative technique. ${ }^{22}$ 
In second level analysis, axial coding, codes that had been split during initial coding were strategically reassembled by the group into a smaller number of code categories identified to illustrate experiences of hospitalists with EL and NTWA. Modifications to the coding scheme were made after differences in the application of codes were identified and adjudicated to $100 \%$ consensus. Responses were then un-blinded to gender, and the coding team met two additional times for selective coding - reviewing axial codes to identify core themes and subthemes by gender. This process resulted in finalization of the coding scheme and codebook.

\section{RESULTS}

\section{Participant Characteristics}

Of eligible respondents receiving an emailed survey link ( $N=$ 272), $51.5 \%$ completed EL items, $47.4 \%$ completed NTWA items, and $41.5 \%$ completed demographic items. Respondents had a binary gender distribution ( $54.9 \%$ women; $39.8 \%$ men) that largely represented the sample population. No participants self-identified as non-binary; six respondents declined to answer. See Table 1 for respondent demographics.

\section{Quantitative Survey Findings}

Of 141 participating hospitalists, $27.9 \%$ reported taking EL at least once during their current employment. Of respondents that completed gender demographic items $(N=113)$, more women reported taking EL compared with men $(p=0.035)$, and also reported taking longer ELs ( $p=0.002) ; 29 \%$ of ELs lasted $<3$ months for women compared to $83.3 \%$ for men. Both men and women cited "birth/adoption of a child" as the main reason for EL. Furthermore, respondent parents who had not taken leave $(N=26)$ were predominantly men $(76.9 \%)$. Half of women (51.6\%) reported at least one child compared with $62.2 \%$ of men. Bivariate analysis of EL and demographics confirmed that self-identification as a woman $(p=0.047)$ and having children $(p<0.001)$ were the two factors significantly associated with taking EL; findings persisted following exclusion of gender nonrespondents $(p=0.035 ; p<0.001)$. Being married was also associated with taking $\operatorname{EL}(p=0.034)$ but did not reach significance after removing gender nonrespondents.

As for NTWA, $74.3 \%$ of respondents described modifying "traditional" hospitalist schedules and/or roles. There was no significant difference between genders in who have experience with at least one NTWA $(p=0.114)$ Women and men shared "birth/adoption of a child" and "burnout" as the most common reasons for NTWA. The most frequently reported NTWA among genders was "change of career focus to a less clinical position (e.g., decreased clinical time in favor of academic or administrative pursuits)." Men and women respondents diverged in utilization of part-time work; women (27.4\%) assumed a part-time schedule more than twice as
Table 1 Demographic Variables in Relation to Extended Leave

\begin{tabular}{|c|c|c|c|}
\hline Participant characteristic, $n(\%)$ & $\begin{array}{l}\text { No EL } \\
(n=76)\end{array}$ & $\begin{array}{l}\mathbf{E L} \\
(n=37)\end{array}$ & $p$ value \\
\hline \multicolumn{3}{|l|}{ Gender } & \multirow[t]{4}{*}{$<0.05$} \\
\hline Woman (she, her) & $37(48.7)$ & $25(67.6)$ & \\
\hline Man (he, him) & $36(47.4)$ & $9(24.3)$ & \\
\hline Prefer not to answer & $3(3.9)$ & $3(8.1)$ & \\
\hline \multicolumn{3}{|l|}{ Number of children } & \multirow[t]{4}{*}{$<.0001$} \\
\hline 0 & $46(60.5)$ & $1(2.7)$ & \\
\hline$\geq 1$ & $27(35.5)$ & $36(97.2)$ & \\
\hline Prefer not to answer & $3(3.9)$ & $2(5.4)$ & \\
\hline \multicolumn{3}{|l|}{ Race } & \multirow[t]{7}{*}{0.81} \\
\hline African American/Black & $2(2.6)$ & 0 & \\
\hline Asian & $13(17.1)$ & $6(16.2)$ & \\
\hline Native Hawaiian/Pacific Islander & $1(1.3)$ & 0 & \\
\hline Other & $3(3.9)$ & $1(2.7)$ & \\
\hline White & $50(65.8)$ & $27(73.0)$ & \\
\hline Prefer not to answer & $7(9.2)$ & $3(8.1)$ & \\
\hline \multicolumn{3}{|l|}{ Ethnicity } & \multirow[t]{4}{*}{0.06} \\
\hline Hispanic/Latinx & $5(6.6)$ & 0 & \\
\hline Not Hispanic/Latinx & $70(92.1)$ & $34(91.9)$ & \\
\hline Prefer not to answer & $1(1.3)$ & $3(8.1)$ & \\
\hline \multicolumn{3}{|l|}{ Marital status } & \multirow[t]{5}{*}{0.03} \\
\hline Single & $17(22.4)$ & $2(5.4)$ & \\
\hline Married & $55(72.4)$ & $31(83.8)$ & \\
\hline Divorced & $3(3.9)$ & $1(2.7)$ & \\
\hline Prefer not to answer & $1(1.3)$ & $3(8.1)$ & \\
\hline \multicolumn{3}{|l|}{ Academic title } & \multirow[t]{6}{*}{0.26} \\
\hline Instructor & $23(30.3)$ & 7 (18.9) & \\
\hline Assistant professor & $35(46.1)$ & $25(67.6)$ & \\
\hline Associate professor & $13(17.1)$ & $5(13.5)$ & \\
\hline Professor & $3(3.9)$ & 0 & \\
\hline Other & $2(2.6)$ & 0 & \\
\hline \multicolumn{3}{|l|}{ Institution } & \multirow[t]{5}{*}{0.07} \\
\hline Site 1 & $34(44.7)$ & $14(37.8)$ & \\
\hline Site 2 & $18(23.7)$ & $17(45.9)$ & \\
\hline Site 3 & $23(30.3)$ & $6(16.2)$ & \\
\hline Prefer not to answer & $1(1.3)$ & 0 & \\
\hline \multicolumn{3}{|c|}{ Years in practice as an academic hospitalist } & \multirow[t]{5}{*}{0.12} \\
\hline$<5$ & $30(39.5)$ & $8(21.6)$ & \\
\hline 5 to 10 & $21(27.6)$ & $14(37.8)$ & \\
\hline$>10$ & $22(28.9)$ & $13(35.1)$ & \\
\hline Prefer not to answer & $3(3.9)$ & $2(5.4)$ & \\
\hline \multicolumn{3}{|l|}{ Age in years } & \multirow[t]{5}{*}{0.25} \\
\hline$\leq 35$ & $29(38.2)$ & $9(24.3)$ & \\
\hline $36-40$ & $14(18.4)$ & $12(32.4)$ & \\
\hline $41-45$ & $15(19.7)$ & $10(27.0)$ & \\
\hline$\geq 46$ & $8(10.5)$ & $3(8.1)$ & \\
\hline
\end{tabular}

often as men (11.4\%). When grouping NTWA strategies into those that may negatively impact career trajectory (i.e., declined an offer for a leadership position)versus those that may positively impact career (i.e., decreased clinical time in favor of academic pursuits), men and women did not significantly differ in NTWA strategies chosen $(p=0.88)$. See Table 2 for quantitative analysis based on gender.

\section{Qualitative Findings}

Within open-text comments describing impacts of EL and NTWA, we identified four overarching domains: personal, career, well-being, and work-life integration. Within each domain, positive and negative impacts were reported. Please see Tables 3 and 4 for a complete list of domains, themes, and subthemes, with representative responses.

Extended Leave. Within the personal domain, both genders described EL having a positive effect on the parenting 
Table 2 Leave Status, Leave Length, and NTWA Strategy in Association with Gender

\begin{tabular}{|c|c|c|c|}
\hline \multicolumn{4}{|l|}{$\overline{\mathbf{E L}}$} \\
\hline & Men $(n=45)$ & Women $(n=62)$ & $p$ value \\
\hline \multicolumn{3}{|l|}{ Leave status: $n(\%) *$} & 0.003 \\
\hline Have taken/currently taking EL & $9(20.0)$ & $25(40.3)$ & \\
\hline Never taken EL & $36(80.0)$ & $37(59.7)$ & \\
\hline \multirow{2}{*}{\multicolumn{3}{|c|}{ Length of leave: $n(\%)^{\dagger}$}} & $p$ value \\
\hline & & & 0.002 \\
\hline 1 to 3 months & $10(83.3)$ & $11(28.9)$ & \\
\hline \multirow[t]{2}{*}{$>3$ months } & $2(16.7)$ & $27(71.1)$ & \\
\hline & NTWA & & \\
\hline \multicolumn{3}{|l|}{ NTWA experience; $n(\%)$} & $\begin{array}{l}p \text { value } \\
0.114\end{array}$ \\
\hline Chosen at least 1 NTWA & 25 & 53 & \\
\hline \multirow[t]{2}{*}{ No experience with NTWA } & 10 & 9 & \\
\hline & $\operatorname{Men}(n=84)$ & Women $(n=126)$ & $p$ value \\
\hline \multicolumn{3}{|l|}{$\begin{array}{l}\text { Career impact: negative and } \\
\text { positive impacts (excluding neutral) } n(\%)^{\ddagger}\end{array}$} & 0.880 \\
\hline \multirow{2}{*}{\multicolumn{3}{|c|}{$\begin{array}{l}\text { leadership; defer academic promotion; } \\
\text { part time; defer training; stepped down from leadership role }\end{array}$}} & \\
\hline & & & \\
\hline Positive: less clinical work & $21(25.0)$ & $37(29.4)$ & \\
\hline
\end{tabular}

*The $n$ for leave status reflects respondents who have ever/currently are taking EL

$t$ The $n$ value for leave length accounts for some respondents taking multiple leaves

$\$$ The $n$ value for career impact reflects each respondent's ability to select multiple NTWA strategies

relationship. Women expressed negative impacts across all four domains whereas men solely noted negative impact to career - a decrease in academic productivity. Within the career domain, women, unlike men, reported workplace bias and harassment related to EL and parenting, lack of academic productivity after return from EL, and within the well-being domain, difficulty balancing competing responsibilities. One woman speculated that parenting itself rather than EL is the primary barrier to maintaining career trajectory.

Non-traditional Work Arrangements. Within the work-life integration domain, both genders associated NTWA with increased schedule flexibility, predictability, and work-life satisfaction. Within the well-being domain, both genders reported burnout prevention. Within the personal domain, respondents of both genders noted that NTWA allowed careers to align with personal priorities. Both genders described positive impacts of NTWA on career advancement. Some women expressed a sense of agency in their decision to pursue a different direction. Several women, however, perceived negative impacts to career relating to academic advancement, promotion, and loss of opportunity and expressed self-doubt regarding clinical and non-clinical identities; similar impacts were not noted by men. Only women expressed secondary concerns about financial impacts of EL and NTWA (Table 4).

\section{DISCUSSION}

Our pilot study of academic hospitalists demonstrated that women respondents took EL significantly more often than men and described a wider range of related negative impacts. Our results also suggest that men and women have similar primary drivers of EL and pursue similar NTWA strategies, with both groups most commonly choosing to decrease clinical time. Men and women described positive impacts of NTWA for all four identified domains, though only women noted negative impacts on their career trajectories.

The gender imbalance among those who take EL reflects institution-level policies and cultural norms emphasizing maternity rather than parental leave. Leave length taken for childbirth as reported by site-level hospitalist administrators was proportionate to the amount of paid leave offered. Participating institutions had vastly different family leave policies regarding whether leave was paid and for how long (see Appendix B for institutional leave policies). Anecdotally, the site with the most gender parity in leave policies also reported the longest average leaves for both genders. Broadening paid leave opportunities for both birthing and adoptive parents and their partners may be a key component of equity in the impacts of nonlinear career paths across genders.

Consistent with comments offered by a single respondent that parenting itself rather than EL may be the larger influencer of career trajectory, Riano et al. postulated that restricting family leave to the primary caregiver forces women to assume the brunt of childrearing responsibilities and could eventually lead to attrition of women from academic medicine. ${ }^{20}$ Though our study did not assess career attrition, the negative career, personal, work-life integration, and well-being impacts of EL disproportionately reported by women are a concerning signal that attrition might follow. In more egalitarian countries such as Sweden, a country that promotes paid paternity leave and encourages shared parenting responsibilities, longer paternity leaves have been associated with greater retention of women within the workforce. ${ }^{23}$ Interestingly, Pylkkänan et al. found equitable leave policies did not necessarily translate to men 
Table 3 Domains, Themes, and Subthemes from Qualitative Analysis of 32 Responses to the Question "What impact, If Any, Has Your Decision to Take Extended Leave Had on Your Career and/or Personal Life?" from a Study of Academic Hospitalists (2020)

\begin{tabular}{|c|c|c|c|}
\hline Domains & Themes & $\begin{array}{l}\text { Subthemes } \\
\text { positiveimpacts }\end{array}$ & Representative quotations \\
\hline \multirow[t]{4}{*}{ Personal } & \multirow[t]{4}{*}{ Relationships } & Parenting & $\begin{array}{l}\text { "...was critical to the foundation of the relationship I have } \\
\text { with my child" (M) }\end{array}$ \\
\hline & & Marriage & "Good for marriage" (M) \\
\hline & & Family time & "It was great to have the time at home with my then infants." (W) \\
\hline & & Empathy & "...helped me to empathize with the struggles of others." (W) \\
\hline \multirow[t]{2}{*}{ Career } & \multicolumn{2}{|c|}{ Supportive work culture } & $\begin{array}{l}\text { "I felt supported by my bosses and colleagues who supported } \\
\text { me taking a full break from work without any lingering } \\
\text { responsibilities" (M) }\end{array}$ \\
\hline & \multicolumn{2}{|l|}{ Gradual on-ramp } & $\begin{array}{l}\text { "I was able to gradually return to work until I was back to } \\
\text { full time at a reduced capacity (70\% FTE)" (M) }\end{array}$ \\
\hline \multirow[t]{3}{*}{ Well-being } & \multirow[t]{2}{*}{ Physical health } & Self & $\begin{array}{l}\text { "Added value to my personal life for...physical recovery } \\
\text { from childbirth." (W,) }\end{array}$ \\
\hline & & Family & $\begin{array}{l}\text { "I was able to fully focus on my family member who } \\
\text { needed help." (M) }\end{array}$ \\
\hline & $\begin{array}{l}\text { Mental health } \\
\text { Personal satisfaction }\end{array}$ & Burnout/stress reduction & $\begin{array}{l}\text { "Helped with burnout." (M) } \\
\text { "Improved satisfaction with bonding period with my } \\
\text { newborns." (W) }\end{array}$ \\
\hline Domains & Themes & $\begin{array}{l}\text { Subthemes } \\
\text { negativeimpacts }\end{array}$ & Representative quotations \\
\hline \multirow[t]{3}{*}{ Personal } & \multirow[t]{3}{*}{ Relationships } & Marriage & $\begin{array}{l}\text { "Since my child was in daycare and frequently was sick } \\
\text { my non physician husband would resent me for having } \\
\text { to take more days off than I would and it put a huge } \\
\text { strain on my mental health and on our marriage." (W) }\end{array}$ \\
\hline & & Household work imbalance & \\
\hline & & Financial strain & $\begin{array}{l}\text { "It's also been devastating personally, undermining } \\
\text { my financial security and identity..." (W) }\end{array}$ \\
\hline \multirow[t]{5}{*}{ Career } & \multirow[t]{2}{*}{ Advancement } & Productivity & $\begin{array}{l}\text { "The leave period slowed my academic productivity, } \\
\text { in spite of continuing to do research/admin work..." (M) }\end{array}$ \\
\hline & & Promotion & $\begin{array}{l}\text { "My first extended leave (not accounted for here) } \\
\text { extended my promotion clock by a year." (W) }\end{array}$ \\
\hline & Opportunity & & $\begin{array}{l}\text { "I have passed up several opportunities, including } \\
\text { applying for leadership roles" (W) }\end{array}$ \\
\hline & Bias and harassment & & $\begin{array}{l}\text { "I have been verbally disparaged by a supervisor } \\
\text { for taking leave ("She'll never come back") which changed } \\
\text { our working relationship and my respect for this person" (W) }\end{array}$ \\
\hline & Focus and interruption & & $\begin{array}{l}\text { "Hard to focus on developing/advancing my career } \\
\text { for a good } 6 \text { months after leave" (W) }\end{array}$ \\
\hline \multirow[t]{4}{*}{ Well-being } & Guilt & & $\begin{array}{l}\text { "Either I feel guilty for not accomplishing things while } \\
\text { on leave, or I feel guilty for adequately devoting } \\
\text { my attentions to the baby" }(W)\end{array}$ \\
\hline & \multirow[t]{2}{*}{ Unmet expectations } & Personal & $\begin{array}{l}\text { "I felt like I was failing at meeting expectations } \\
\text { of both my work and my family" (W) }\end{array}$ \\
\hline & & Peer comparison & $\begin{array}{l}\text { "Resulted in me advancing less than peers who } \\
\text { have not taken leave..." (W) }\end{array}$ \\
\hline & Mental health & & $\begin{array}{l}\text { "Ultimately I hit rock bottom from post-partum } \\
\text { depression...." (W) }\end{array}$ \\
\hline Work-life integration & Boundary violation & & $\begin{array}{l}\text { "Pressure to continue administrative work } \\
\text { while on leave" (W) }\end{array}$ \\
\hline
\end{tabular}

$M$ men, $W$ women

taking longer leaves, suggesting that specific encouragement of men to take parental leave is also necessary to promote gender equality within the workforce.

Our qualitative analysis highlights stark differences between genders in their experiences related to EL. Only women reported workplace bias and harassment after returning from leave, which contributed to loss of opportunity, previously described among women academic hospitalists. ${ }^{24}$ These observations support other accounts of pervasive bias and discrimination of women physicians not limited to EL. ${ }^{25,26}$ Gottenborg et al. suggested creating a flexible "ramp-up and ramp-down" period for clinical work surrounding leave to account for "the challenges of pregnancy and new motherhood." ${ }^{24}$ However, some of our respondents felt that such a period (given the inability to "jump back into" non-clinical projects immediately) might widen the productivity gap in comparison with peers that have not taken leave.

Unlike prior descriptions of women in medicine utilizing flexible work arrangements more often than men, ${ }^{11}$ our study suggests that men and women pursue NTWA at similar rates. Both genders described benefit from the accompanying schedule flexibility that allows for more family time and the ability to mold a career better aligned with personal values. Women who pursued NTWA described weakened confidence regarding their clinical and non-clinical capabilities, which may be a driver or consequence of these schedule alterations. Our findings mirror those of Pololi et al. who observed that women physicians across all academic ranks perceived lower self- 
Table 4 Domains, Themes, and Subthemes from Qualitative Analysis of 88 Responses to the Question "What Impact, If Any, Has Your Decision to Take a Non-traditional Work Arrangement Had on Your Career and/or Personal Life?" From a Study of Academic Hospitalists (2020)

\begin{tabular}{|c|c|c|c|}
\hline Domains & Themes & $\begin{array}{l}\text { Subthemes } \\
\text { positiveimpacts }\end{array}$ & Representative quotes \\
\hline \multirow[t]{3}{*}{ Personal } & Relationships & Parenting & $\begin{array}{l}\text { "My decisions have allowed me to be active in my } \\
\text { child's life as a parent" ( } M)\end{array}$ \\
\hline & & Marriage and family & $\begin{array}{l}\text { "Working weekends as a hospitalist really strains marriage } \\
\text { and family time. Opting to pursue a leadership role with } \\
\text { protected time allowed for more weekends spent at home." (W) }\end{array}$ \\
\hline & Agency & & $\begin{array}{l}\text { "I feel more agency in myself and ability to turn away } \\
\text { from the dedicated path." (W) }\end{array}$ \\
\hline \multirow[t]{5}{*}{ Career } & Professional balance & & $\begin{array}{l}\text { "Administrative role helps balance the workload of } \\
\text { the clinical role." }(W)\end{array}$ \\
\hline & Focus & & "Allowed me to pursue my career interest in medicine" (M) \\
\hline & Opportunity & & "increased access to research opportunities" (W) \\
\hline & Advancement & Further training & "I did it to [pursue] master's degree." (W) \\
\hline & & Productivity & $\begin{array}{l}\text { "helped me to be more productive from scholarly } \\
\text { standpoint" (M) }\end{array}$ \\
\hline \multirow[t]{5}{*}{ Well-being } & Health/self-care & Mental & $\begin{array}{l}\text { "I love the balance of my career between clinical and } \\
\text { academic work, it prevents burnout in either role" (W) }\end{array}$ \\
\hline & & Physical & "I am able to exercise regularly" $(W)$ \\
\hline & & Social & $\begin{array}{l}\text { "It has afforded me more time to pursue hobbies and } \\
\text { personal engagements outside of medicine." (W) }\end{array}$ \\
\hline & Satisfaction & Personal & $\begin{array}{l}\text { "More satisfaction and mental strength to now focus on } \\
\text { work as well as additional support from my family" (M) }\end{array}$ \\
\hline & & Professional & $\begin{array}{l}\text { "I enjoy my clinical time more than I feel I would } \\
\text { if I was full-time." (W) }\end{array}$ \\
\hline \multirow[t]{5}{*}{ Work-life integration } & Schedule & Flexibility & "Allowed me more flexibility as the default caregiver" (W) \\
\hline & & Predictability & $\begin{array}{l}\text { "non-clinical work allows for a more traditional } \\
\text { Mon- Fri schedule" (W) }\end{array}$ \\
\hline & & Minimize weekends & "Fewer weekend work obligations" (W) \\
\hline & Minimized tension & & $\begin{array}{l}\text { "It has provided more of a balance between work } \\
\text { life and home life." (W) }\end{array}$ \\
\hline & Boundary setting & & $\begin{array}{l}\text { "I can give more to my institution, but believe that } \\
\text { taking on additional workload will be detrimental } \\
\text { to my work/life balance" (M) }\end{array}$ \\
\hline Domains & Themes & $\begin{array}{l}\text { Subthemes } \\
\text { negativeimpacts }\end{array}$ & Representative quotes \\
\hline \multirow[t]{5}{*}{ Personal } & Relationships & Parental regret & $\begin{array}{l}\text { "...has required me to miss some events of my children } \\
\text { and for that I have some regrets." (M) }\end{array}$ \\
\hline & & Family time & "Increased weekend work reduces time spent with family" (M) \\
\hline & Identity & Impostor syndrome & $\begin{array}{l}\text { "when I am on non-clinical responsibilities, I feel } \\
\text { like an imposter without the correct talents/skills to do that work" (W) }\end{array}$ \\
\hline & & Clinical confidence & $\begin{array}{l}\text { "I definitely feel a loss of my clinician identity and } \\
\text { worry about losing my clinical skills." }(W)\end{array}$ \\
\hline & Financial strain & & $\begin{array}{l}\text { "We've also taken our kid out of daycare in favor of } \\
\text { a nanny in order for us to focus more on our careers } \\
\text { which has...significantly decreased our savings." (W) }\end{array}$ \\
\hline \multirow[t]{2}{*}{ Career } & Advancement & Promotion & $\begin{array}{l}\text { "My promotions track has definitely slowed down } \\
\text { as a result" (W) }\end{array}$ \\
\hline & & Opportunity & $\begin{array}{l}\text { "I feel the loss of opportunity from not being as able } \\
\text { to adopt flexible schedules, take on additional projects, } \\
\text { or network like my colleagues" (W) }\end{array}$ \\
\hline \multirow[t]{3}{*}{ Work-life integration } & Workload & Work shifting & $\begin{array}{l}\text { "I do...take a lot more work home, and work much } \\
\text { more frequently in the evenings after bedtime." (W) }\end{array}$ \\
\hline & & Increased hours & $\begin{array}{l}\text { "While I work more total hours, the work is less intense } \\
\text { and more flexible." (W) }\end{array}$ \\
\hline & Boundary violation & & $\begin{array}{l}\text { "Administrative work has allowed more time with family, } \\
\text { but blurred the lines between work and home" (M) }\end{array}$ \\
\hline
\end{tabular}

$M$ men, Wwomen

efficacy for career advancement. ${ }^{27}$ They also align with findings of personal doubt regarding professional identity previously described among part-time women hospitalists. ${ }^{28}$ Though the impacts of NTWA may be confounded in hospital medicine by a largely shift-based work structure perhaps viewed as in itself "non-traditional,"1 these findings are noteworthy. We do not wish to implicate women themselves in these difficulties. Rather, our observations direct us toward larger questions regarding the veracity of the so-called confidence gap between women and $\operatorname{men}^{29}$ and the culpability of institutions and society at large in perpetuating gender stereotypes.

Our study has several strengths. To our knowledge, this is the first study that describes and compares experiences of academic hospitalist physicians in regard to nonlinear career paths. Three academic centers across the USA participated; we believe that our results are generalizable to the academic hospitalist community at large. Although this work occurred 
during the COVID-19 pandemic, we had a strong response rate from a population disproportionately impacted by increases in clinical demand, perhaps reflecting the importance of this topic within our target population. The survey was also designed to capture academic hospitalist physician experience across the gender spectrum, distinguishing it from many publications on gender equity within hospital medicine and beyond.

This pilot study was limited by its relatively small sample of physicians. Moreover, while we included non-binary options for gender self-identification, the majority of respondents identified as a man or woman. This finding is not unexpected. Given that transgender and gender non-binary individuals are estimated to represent less than $2 \%$ of the overall population, ${ }^{30}$ they may perceive a risk to anonymity with self-identification. Demographics reflected the largest group of respondents at the assistant professor rank, despite relative parity across ranges of years of practice. We attribute these findings to differing institutional promotional requirements (i.e., a participating site with a non-binding timeline), but cannot exclude that nonlinear career paths directly impeded academic promotion where a strict timeline exists. Differing institutional response rates may have skewed results regarding EL utilization and impact, as institutions varied in their policies on paid leave. Though it is possible that family status and not gender is driving reported results, this is not true within our sample where a greater percentage of men than women reported at least one child. Furthermore, evidence supports that single compared to partnered women take leave for different reasons but at similar rates and often suffer even greater career and financial penalties. ${ }^{15}$ Finally, we could not specifically define NTWA within the context of hospital medicine, but allowed respondents to define this for us within the construct of our survey. Qualitative investigation with structured or unstructured interviews would be required to better understand how respondents define NTWA.

Pursuit of nonlinear career paths in hospital medicine may be a double-edged sword for women. It has been offered that "such norms perpetuate gender segregation at work as "part-time jobs remain predominantly female.",31 However, some authors note that nonlinear career paths advance representation in the workforce by allowing women to participate who might otherwise be subject to attrition due to competing responsibilities. ${ }^{32}$ Given evidence of improved patient outcomes when women physicians deliver hospital care, ${ }^{33}$ institutional and national support for creating a culture in which nonlinear career paths do not threaten advancement in hospital medicine is a workforce imperative. Such support will include, at a minimum, inclusive recruitment processes, equitable allocation of career opportunities, reexamination of promotional criteria and timelines, holistic mentorship, and support for personal needs, including childcare and caregiving.

\section{CONCLUSION}

As might be expected, our study found that women academic hospitalists reported taking extended leave twice as often as men. More surprisingly, men addressed burnout and childbearing by utilizing non-traditional work arrangements at similar rates. Women, however, described disproportionately more adverse personal, career, work-life integration and well-being impacts, including bias and discrimination, career impediment, and identity uncertainty. Our findings lay the groundwork for additional exploration of cultural and policy interventions, particularly improved paid leave policies, which may minimize gender disparities in academic hospital medicine as the field continues to mature.

Corresponding Author: Maya V. Defoe, MD; Division of Hospital Medicine, Northwestern University Feinberg School of Medicine, Chicago, IL, USA (e-mail: maya.defoe@nm.org).

Supplementary Information The online version contains supplementary material available at https://doi.org/10.1007/s11606-02207402- $x$.

\section{Declarations:}

Conflict of Interest: The authors declare that they do not have a conflict of interest.

\section{REFERENCES}

1. Levinson W, Linzer $\mathbf{M}$. What is an academic general internist? Career options and training pathways. JAMA. 2002;288(16):2045-2048.

2. Glasheen JJ, Misky GJ, Reid MB, Harrison RA, Sharpe B, Auerbach A. Career satisfaction and burnout in academic hospital medicine. Arch Intern Med. 2011;171(8):782-785.

3. Kane L. 'Death by 1000 Cuts': Medscape National Physician Burnout \& Suicide Report 2021. Medscape. https://www.medscape.com/ slideshow/2021-lifestyle-burnout-6013456\#17. Published 2021.

4. Jolly S, Griffith KA, DeCastro R, Stewart A, Ubel P, Jagsi R. Gender differences in time spent on parenting and domestic responsibilities by high-achieving young physician-researchers. Ann Intern Med. 2014;160(5):344-353.

5. Guille C, Frank E, Zhao Z, et al.Work-family conflict and the sex difference in depression among training physicians. JAMA Intern Med. 2017;177(12): 1766-1772.

6. Viamonte Ros A, Markham S, Wu D, Nicholas P. A rapid scoping review of gender inequities in the medical profession. Nursing \& Health Science Research Journal. 2019;2(1):12-20.

7. Raj A, Carr PL, Kaplan SE, Terrin N, Breeze JL, Freund KM. Longitudinal analysis of gender differences in academic productivity among medical faculty across 24 medical schools in the United States. Acad Med. 2016;91(8):1074-1079.

8. Burden M, Frank MG, Keniston A, et al. Gender disparities in leadership and scholarly productivity of academic hospitalists. J Hosp Med. 2015;10(8):481-485.

9. Weaver AC, Wetterneck TB, Whelan CT, Hinami $\mathbf{K}$. A matter of priorities? Exploring the persistent gender pay gap in hospital medicine. J Hosp Med. 2015;10(8):486-490.

10. Frank E, Zhao Z, Sen S, Guille C. Gender disparities in work and parental status among early career physicians. JAMA Netw Open. 2019;2(8):e198340.

11. Hewlett S, Buck Luce C, Shiller P, Southwell S. The hidden brain drain off-ramps and on-ramps in women's careers. In. Harvard Business Review. Vol March 2005:1-140. 
12. Job Flexibilities and Work Schedules 2017-2018: Data from the American Time Use Survey. Bureau of Labor Statistics. https://www.bls.gov/news. release/flex2.nr0.htm. Published 2019. Updated September 24, 2019. .

13. Hewlett S, Buck Luce C. Off-ramps and on-ramps: keeping talented women on the road to success. In. Harvard Business Review. Vol March 2005.

14. Ahmad S. Family or future in the academy? Review of Educational Research. 2017;87:204-239.

15. Herr J, Klerman JA. Gender Differences in Needing and Taking Leave. Rockville, MD2020.

16. Walton GM, Cohen GL. A question of belonging: race, social fit, and achievement. J Pers Soc Psychol. 2007;92(1):82-96.

17. Fassiotto $\mathbf{M}$, Hamel EO, Ku M, et al. Women in academic medicine: measuring stereotype threat among junior faculty. J Womens Health (Larchmt). 2016;25(3):292-298.

18. Steele CM, Aronson J. Stereotype threat and the intellectual test performance of African Americans. J Pers Soc Psychol. 1995;69(5):797811

19. Gilovich T, Keltner D, Nisbett RE. Social Psychology. New York, NY: W. W. Norton; 2006.

20. Riano NS, Linos E, Accurso EC, et al. Paid family and childbearing leave policies at top US medical schools. JAMA. 2018;319(6):611-614.

21. Glazer B, Strauss A. The Discovery of Grounded Theory: Strategies for Qualitative Research. Chicago: De Gruyter; 1967.

22. Kolb S. Grounded theory and the constant comparative method: valid research strategies for educators. J Emerg Trends in Educ Res Pol Stud. 2012;3(1):83-86.

23. Pylkkänen E, Smith N. Career interruptions due to parental leave: a comparative study of Denmark and Sweden. OECD Social, Employment and Migration Working Papers. 2003;1.

24. Gottenborg E, Maw A, Ngov LK, Burden M, Ponomaryova A, Jones CD. You can't have it all: the experience of academic hospitalists during pregnancy, parental leave, and return to work. J Hosp Med. 2018;13(12):836-839.
25. Adesoye T, Mangurian C, Choo EK, et al. Perceived discrimination experienced by physician mothers and desired workplace changes: a cross-sectional survey. JAMA Intern Med. 2017;177(7):1033-1036.

26. Bhandari S, Jha P, Cooper C, Slawski B. Gender-based discrimination and sexual harassment among academic internal medicine hospitalists. J Hosp Med. 2021;16(2):84-89.

27. Pololi LH, Civian JT, Brennan RT, Dottolo AL, Krupat E. Experiencing the culture of academic medicine: gender matters, a national study. J Gen Intern Med. 2013;28(2):201-207.

28. Ozbilgin MF, Tsouroufli M, Smith M. Understanding the interplay of time, gender and professionalism in hospital medicine in the UK. Soc Sci Med. 2011;72(10):1588-1594.

29. Guillen $\mathbf{L}$. Is the confidence gap between men and women a myth? In. Harvard Business Review2018.

30. Goodman M, Adams N, Corneil T, Kreukels B, Motmans J, Coleman E. Size and distribution of transgender and gender nonconforming populations: a narrative review. Endocrinol Metab Clin North Am. 2019;48(2):303-321.

31. Lewis S. Restructuring workplace cultures: The ultimate work-family challenge? Women In Management Review. 2001;16:21-29.

32. In: Hakim C, Blossfeld H, eds. Between Equalization and Marginalisation: Women Working Part-Time in Europe and the United States of America. New York: Oxford University Press; 1997.

33. Tsugawa Y, Jena AB, Figueroa JF, Orav EJ, Blumenthal DM, Jha AK. Comparison of hospital mortality and readmission rates for Medicare patients treated by male vs female physicians. JAMA Intern Med. 2017; 177(2):206-213.

Publisher's Note: Springer Nature remains neutral with regard to jurisdictional claims in published maps and institutional affiliations. 